\title{
The case for a pulmonary valve in neonatal and young infant primary tetralogy of Fallot repair: Does it make a difference?
}

\author{
Ibrahim Abdullah, MD
}

\footnotetext{
From the Department of Pediatric Cardiothoracic Surgery, Banner Children's, Cardon Children's Medical Center, Mesa, Ariz.

Disclosures: Author has nothing to disclose with regard to commercial support.

Received for publication Oct 9, 2017; accepted for publication Oct 20, 2017; available ahead of print Nov 17, 2017.

Address for reprints: Ibrahim Abdullah, MD, Department of Pediatric Cardiothoracic Surgery, Banner Children's, Cardon Children's Medical Center, 1432 S Dobson Rd, Mesa, AZ 85202 (E-mail: iabdullah1234@ gmail.com). J Thorac Cardiovasc Surg 2018;155:735-6

$0022-5223 / \$ 36.00$

Copyright (c) 2017 by The American Association for Thoracic Surgery

https://doi.org/10.1016/j.jtcvs.2017.10.056
}

In this issue of the Journal, Balasubramanya and colleagues ${ }^{1}$ from Boston Children's Hospital share a rich experience of primary tetralogy of Fallot (TOF) repair in neonates and young infants during a period of 10 years. Although there may still be debate regarding the merits of primary repair for TOF versus staged repair, the improvement in cardiopulmonary bypass techniques has certainly lent weight to the argument for early primary repair. ${ }^{2}$ The approach taken to the pulmonary valve in primary repair for TOF, however, is still controversial. I remember during my fellowship years in Boston that there was renewed enthusiasm for trying to preserve the pulmonary valve in TOF repair with pulmonary stenosis (PS). Hybrid techniques were used to try to preserve the valve. ${ }^{3}$ At the most recent American Association for Thoracic Surgery meeting in Boston, however, I was intrigued to hear of the unexpected high incidence of pulmonary valve failure on intermediate follow-up of the Boston hybrid valve-sparing repair (VSR) technique. ${ }^{4}$ Although I carried the Boston VSR technique in early primary repair with conviction into my practice, the recent results from Boston have made me question the valve-sparing paradigm. On one side are the long-term inherent risks of a transannular patch (TAP), resulting in free pulmonary insufficiency with consequent right ventricular enlargement and failure. On the other side, continued right ventricular outflow tract obstruction with a small but possibly competent pulmonary valve or midterm pulmonary valve insufficiency may necessitate frequent earlier reintervention.

In this review, 2 subgroups are considered: TOF with PS and TOF with pulmonary atresia (PA). In the TOF with PS subgroup, patients underwent either a VSR or a TAP. In the TOF with PA subgroup, patients underwent placement of a right ventricular-pulmonary arterial (RVPA) conduit or a TAP. In essence, both subgroups compared those neonates and young infants who underwent early primary repair with a pulmonary valve remaining in circulation (VSR or RV-PA conduit) with those who did not have a pulmonary valve remaining in

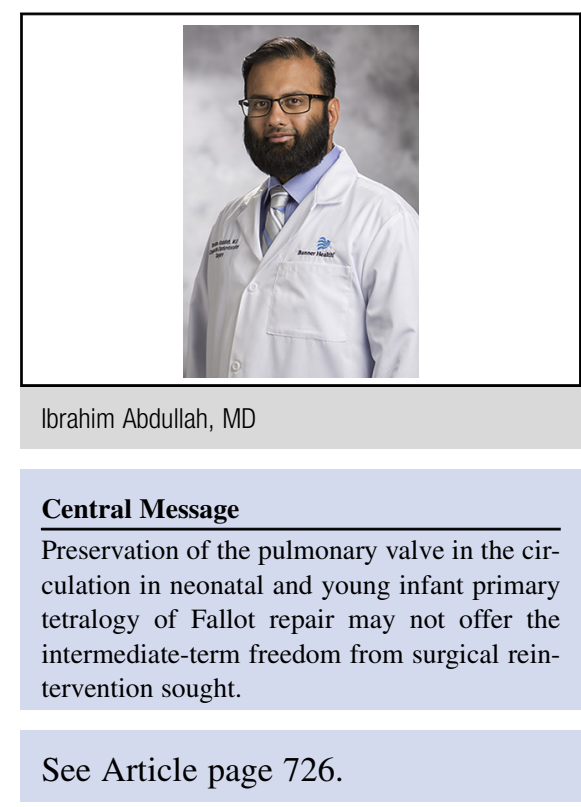

circulation (TAP). It is interesting to note that there was no difference in right ventricular outflow tract reintervention rates between patients with VSR and those with TAP in the TOF with PS subgroup, whereas in the VSR subcategory there was a higher rate of surgical reintervention for lower birth weight patients $(2.5 \mathrm{~kg}$ vs $3.7 \mathrm{~kg}$ ). Furthermore, there was a higher and earlier incidence of right ventricular outflow tract surgical reinterventions for RV-PA conduits than for TAP in the TOF with PA subgroup. This naturally prompts the question: Is there a benefit to a technique that attempts to keep a pulmonary valve in circulation after a primary repair (VSR or RV-PA conduit) versus one that does not (TAP)? Maybe the classic technique of a TAP offers enhanced freedom from reintervention in the short to intermediate term. Maybe the choice of technique needs to be tailored to each patient's unique anatomy. Certainly, those with small branch pulmonary arteries or hypoplastic lungs may not tolerate the lack of a pulmonary valve. One cannot dismiss, however, the fact that the classic TAP approach continues to carry time-tested validation. This experience from Boston will no doubt continue to add to this debate.

\section{References}

1. Balasubramanya S, Zurakowski D, Borisuk M, Kaza AK, Emani SM, del Nido PJ, et al. Right ventricular outflow tract reintervention after primary tetralogy of Fallot repair in neonates and young infants. J Thorac Cardiovasc Surg. 2018; 155:726-34. 
2. Barrat-Boyes BG, Neutze JM. Primary repair of tetralogy of Fallot in infancy using profound hypothermia with circulatory arrest and limited cardiopulmonary bypass: a comparison with conventional two stage management. Ann Surg. 1973;178:406-11.

3. Bautista-Hernandez V, Cardenas I, Martinez-Bendayan I, Loyola H, Rueda F, Portela F. Valve-sparing tetralogy of Fallot repair with intraoperative dilation of the pulmonary valve. Pediatr Cardiol. 2013;34:918-23.
4. Hofferberth SC, Nathan M, Sleeper LA, Marshall AC, Baird CW, et al. Valvesparing repair with intraoperative balloon dilation in tetralogy of Fallot: midterm results and therapeutic implications. Presented at: 97th Annual Meeting of The American Association for Thoracic Surgery; May 1, 2017; Boston, Mass. Available at: http://aats.org/aatsimis/AATS/Meetings/Active_Meetings/Centennial/ Preliminary\%20Program/Abstracts/16\%20New.aspx. 